The IMPACt Of COVID in Higher Education

\title{
Work environment during the COVID-19 pandemic in Saudi Arabia
}

\author{
Rehab Aburas \\ Interior Design Engineering Department, College of Architecture and Design, Prince Sultan University, Saudi \\ Arabia
}

\begin{abstract}
Background: COVID-19 is affecting all spheres of life. As of 8 September 2020, there have been 321,595 confirmed cases of COVID-19 and 4,107 deaths in Saudi Arabia. The concerns regarding work from offices and contacting others is a global concern during this pandemic. Most of workers are mainly concerns about getting infected and spread it to their families. Therefore, to cope with the COVID-19 pandemic, architects, urban planners, and designers have already switched their attention to visualizing the post-pandemic era; however, there are inadequate studies on how the antivirus-built environment will look. Accordingly, this study aims to reflect on perceptions of the work environment during the COVID-19 pandemic in Saudi Arabia.

Design and Methods: An online questionnaire consisting of five questions was designed to collect the data and was distributed via SurveyMonkey in August 2020. Research ethics approval was sought from the institutional review board. A total of 87 respondents participated in this study.

Results: The result shows that $57.83 \%$ of respondents were female and $42.17 \%$ were male. The majority of the respondents were from the public sector $(49.40 \%$ - public sector, $43.37 \%$ private sector, and $7.23 \%$ - other sectors). Overall, female participants were more concerned about work environments during the pandemic. Most of the participants were working in individual offices.

Conclusion: The virus does not discriminate by gender. In order to respond effectively to the crisis, we need a whole-society approach to understand its differential impact on women and men. The findings will encourage policymakers and business owners to respond to the areas highlighted in this study as causing concern such as elevators, restrooms, and common areas.
\end{abstract}

\section{Introduction}

According to Agius et al., the World Health Organization has so far prepared a surveillance protocol only for healthcare workers, and no international case definition for attributing an occupa- tional origin to COVID-19 cases. This result shows many workers who lack a comparable degree of protection subject to not working from home. ${ }^{1,2} \mathrm{Up}$ to now, there are scarce studies on how the antivirus-built environment will look, thus urban planners and designers are switching their attention to visualizing the post-pandemic era. ${ }^{3}$ Obtaining insights from the users of the work settings well help designers to modify and address the concerns in the zoning, space layout, and other design elements. In this study for instance, it was assumed that having individual offices (with four walls) will consider the safest choice in regard to social distancing and contacting others, but the participants who are working individual offices expressed their concerns, and sometime even higher than those who work in cubicle with low-high partitions. It is also observed that participants who are working individual offices representing negative $t$ value of Paired Samples Test $(t=-2.089)$ meaning they have higher overall concerns. Therefore, the designers should look into more creative solutions such as the choices of materials and finishes.

The concerns regarding work from offices is a global concern, and these concerns were mainly the fear of getting infected and spread it to their families. For example, a recent descriptive study investigates the epidemiological characteristics of a cluster epidemic of COVID-19 in a collective workplace in Tianjin, China. The study analysed ten confirmed COVID-19 cases in the workplace, and the epidemic had spread from the workplace to four families, infecting 7 family members within four days median exposure-onset interval. ${ }^{4}$ Therefore, working environments around the world have been altered since the appearance of COVID-19. As its spread increased, many firms adapted remote working, a relatively new mode of work arrangements that were developed in the 1970s. ${ }^{5}$ Working from home has been implemented to reduce social contact; however, stay-at-home regulations have been challenging for some workers, for example workers living in smaller houses. Therefore, to cope with the COVID19 pandemic, architects, urban planners, and designers have already switched their attention to visualizing the post-pandemic era. For years, the amount of privacy allocated to each office worker has been gradually reduced as companies have brought in open-plan offices. ${ }^{6}$

Significance for public health

There are inadequate studies on how the antivirus-built environment will look, therefore; architects, urban planners, and designers have already switched their attention to visualizing the post-pandemic era. In the background of the ongoing COVID-19 pandemic globally, and increased disruption in work environments, this study reflects several issues of concern in work environments during the COVID-19 in Saudi Arabia. The area causing most concern was the elevator and the one causing least concern was meeting rooms. Importantly, male participants were less concerned about the office than female participants. The female group may be adversely affected in relation to work environments due to COVID-19, being increasingly susceptible to associated health risks. These findings hold vital potential for understanding gender perceptions on the work environment during a pandemic like COVID-19. 
Companies have applied technology and smart solutions to virtual world applications and accommodate employees' needs to work remotely; however, working from home can be challenging and workers might face difficulties when dealing with new technologies. ${ }^{7-10}$ For instance in UK, there was fear that home broadband networks would collapse under the weight of usage by service providers; trade bodies stated that evening peak activity, when the nation sits down to stream Netflix and play online video games, is often ten times the typical daytime demand. ${ }^{11}$ Although working from home benefits many workers and reduces pollution, the longterm impact is unclear and needs further investigation. ${ }^{12}$ Also, as the pandemic continues and remote working becomes the new norm, office space might need to be modified to allow more space between workers and fewer seating options. ${ }^{12,13}$

In this paper, a survey was conducted to obtain to explore workers' points of view about the safety of going back to work in offices, and to obtain their suggestions about how they might feel safer in work environments.

\section{Design and methods}

To achieve the objective of this study on reflecting the perceptions of the work environment during the COVID-19 pandemic in Saudi Arabia, a survey questionnaire method was utilized. Initially, the survey questionnaire contains seven questions and with the feedback of two independent researchers and a group of participants $(n=10)$, the final questionnaire contains questions was designed to collect the data. Two questions were demographic: gender and work sector. The third question addressed the type of workspace, and the fourth question ranked the different spaces in the work environment on the following scale: totally safe, safe to some extent, not sure about safety. The final question was an open question designed to allow participants to present their suggestions about making their work environments feel safer. The questionnaire was distributed via email and text messages. The number of statistical tests were performed to assess the validity and reliability of the questionnaire for this study. Participants $t$-test was employed to determine significant differences between the group means $(p<0.001)$. Chi-square test was used in establishing whether the distribution of gender differed significantly between the two groups $(\mathrm{p}<0.05)$. The effect of the differences in age gender on the results was checked by an analysis of covariance (ANCOVA), with significance level set at $p<0.05$. The survey reliability was also tested by Cronbach's alpha, and the result was 0.817 , which is close to 1 , meaning that the survey is reliable. The qualitative part was analysed, and the emergent themes were presented in the discussion section. It is true that common methods bias arises due to the fact that participants are asked to report their own perceptions on two or more constructs in the same survey. This is likely to produce spurious correlations among the items measuring these constructs owing to response styles, and social desirability. To reduce this common methods bias, the study included an open questionnaire to shed more insights of the topic.

\section{Results}

The result indicates that $57.83 \%$ of respondents were female and $42.17 \%$ were male. The majority of the respondents were from the public sector $(49.40 \%$ - public sector, $43.37 \%$ - private sector, and $7.23 \%$ - other sectors). As for the type of offices, the highest percentage score for safety was for working in individual offices at $36 \%$. The score for cubicles with no partition was $35 \%$, and for cubicles with high partitions, $16 \%$. Other options included working from meeting rooms, working from home, and working in a workshop or a clinic exam room.

Table 1 shows the overall descriptive statistics of areas of concern in regard to the safety of working in the office. The areas causing most concern are shown in mean rank order: elevators (2.52), restrooms (2.41), common areas (2.38), food beverage areas (2.32), the office (2.28), and meeting rooms (2.22).

As for gender differences (Table 2), females were most concerned with restrooms (2.65) and elevators (2.61). On the other hand, males were more concerned with two areas, but with a lower mean score than females, namely elevators (2.36) and common areas (2.21). Further, male participants were less concerned about the office environment (1.97) and meeting rooms (1.94) than females (2.46 and 2.39, respectively).

Participants were asked about their main concerns when working from the office, and how many spaces listed in this question they as rated totally safe, safe to some extent, and not sure about safety (Table 3). In general, the most concern was expressed about using elevators: $57.83 \%$ were not sure about the safety of using them. Also, $57.83 \%$ not sure about the safety of using common areas such as waiting or reception areas. While $20.73 \%$ thought working from the office is totally safe, $47.56 \%$ were not sure about the safety of working from the office. While $42.17 \%$ were not sure

Table 1. Overall descriptive statistics for all participants.

\begin{tabular}{|c|c|c|c|c|c|c|}
\hline Area of concern & $\begin{array}{c}N \\
\text { Statistic }\end{array}$ & $\begin{array}{l}\text { Minimum } \\
\text { Statistic }\end{array}$ & $\begin{array}{l}\text { Maximum } \\
\text { Statistic }\end{array}$ & $\begin{array}{c}\text { Mean } \\
\text { Statistic }\end{array}$ & $\begin{array}{l}\text { Std. deviation } \\
\text { Statistic }\end{array}$ & $\begin{array}{l}\text { Variance } \\
\text { Statistic }\end{array}$ \\
\hline Office & 87 & 1 & 3 & 2.28 & 0.788 & 0.621 \\
\hline Meeting rooms & 87 & 1 & 3 & 2.22 & 0.754 & 0.568 \\
\hline Food and beverage areas & 87 & 1 & 3 & 2.32 & 0.723 & 0.523 \\
\hline Restrooms & 87 & 1 & 3 & 2.41 & 0.771 & 0.594 \\
\hline Elevators & 87 & 1 & 3 & 2.52 & 0.760 & 0.578 \\
\hline Common areas & 87 & 1 & 3 & 2.38 & 0.751 & 0.564 \\
\hline Office layout & 87 & 1 & 4 & 2.24 & 1.078 & 1.162 \\
\hline Valid N (listwise) & 87 & & & & & \\
\hline Concern about common areas & $\begin{array}{c}\text { Male } \\
\text { Female }\end{array}$ & $\begin{array}{l}2.21 \\
2.48 \\
\end{array}$ & $\begin{array}{l}0.820 \\
0.693 \\
\end{array}$ & $\begin{array}{l}0.143 \\
0.094 \\
\end{array}$ & & \\
\hline
\end{tabular}


about the safety of using meeting rooms, $20.48 \%$ thought meeting rooms are totally safe. While $55.42 \%$ were not sure about the safety of restrooms, $16.87 \%$ thought restrooms are totally safe. The Table 3 shows the rating percentage of each type of space.

Finally, Table 4 shows the significant differences in opinion on various areas of concern using the independent samples Kolmogorov-Smirnov Test (Figure 1). The null hypothesis was that there were no significant differences on areas of concern between males and females. Importantly, the results indicate that a null hypothesis is retained for five areas of concern: the office,

Table 2. Descriptive statistics by gender.

\begin{tabular}{lllccc} 
Area of concern & Gender & $N$ & Mean & Std. deviation & Std. error mean \\
Office & Male & 33 & 1.97 & 0.847 & 0.147 \\
& Female & 54 & 2.46 & 0.693 & 0.094 \\
Meeting rooms & Male & 33 & 1.94 & 0.788 & 0.137 \\
& Female & 54 & 2.39 & 0.827 & 0.093 \\
\hline Food and beverage areas & Male & 33 & 2.06 & 0.606 & 0.144 \\
& Female & 54 & 2.48 & 0.810 & 0.083 \\
Restrooms & Male & 33 & 2.03 & 0.649 & 0.083 \\
& Female & 54 & 2.65 & 0.822 & 0.143 \\
Elevators & Male & 33 & 2.36 & 0.712 & 0.097 \\
\multirow{2}{*}{ Common Areas } & Female & 54 & 2.61 & 0.820 & 0.143 \\
& Male & 33 & 2.21 & 0.693 & 0.094 \\
\hline
\end{tabular}

Table 3. Participants' concerns when started working from offices.

\begin{tabular}{|c|c|c|c|c|}
\hline Area of concern & & Observed $N$ & Expected $N$ & Residual \\
\hline Office & $\begin{array}{l}\text { Totally safe } \\
\text { To some extent safe } \\
\text { Not sure about safety } \\
\text { Total }\end{array}$ & $\begin{array}{l}18 \\
27 \\
42 \\
87\end{array}$ & $\begin{array}{l}29.0 \\
29.0 \\
29.0\end{array}$ & $\begin{array}{l}-11.0 \\
-2.0 \\
13.0\end{array}$ \\
\hline Meeting rooms & $\begin{array}{l}\text { Totally safe } \\
\text { To some extent safe } \\
\text { Not sure about safety } \\
\text { Total }\end{array}$ & $\begin{array}{l}17 \\
34 \\
36 \\
87\end{array}$ & $\begin{array}{l}29.0 \\
29.0 \\
29.0\end{array}$ & $\begin{array}{c}-12.0 \\
5.0 \\
7.0\end{array}$ \\
\hline Food and beverage areas & $\begin{array}{l}\text { Totally safe } \\
\text { To some extent safe } \\
\text { Not sure about safety } \\
\text { Total }\end{array}$ & $\begin{array}{l}13 \\
33 \\
41 \\
87\end{array}$ & $\begin{array}{l}29.0 \\
29.0 \\
29.0\end{array}$ & $\begin{array}{c}-16.0 \\
4.0 \\
12.0\end{array}$ \\
\hline Restrooms & $\begin{array}{l}\text { Totally safe } \\
\text { To some extent safe } \\
\text { Not sure about safety } \\
\text { Total }\end{array}$ & $\begin{array}{l}15 \\
21 \\
51 \\
87\end{array}$ & $\begin{array}{l}29.0 \\
29.0 \\
29.0\end{array}$ & $\begin{array}{l}-14.0 \\
-8.0 \\
22.0\end{array}$ \\
\hline Elevators & $\begin{array}{l}\text { Totally safe } \\
\text { To some extent safe } \\
\text { Not sure about safety } \\
\text { Total }\end{array}$ & $\begin{array}{l}14 \\
14 \\
59 \\
87\end{array}$ & $\begin{array}{l}29.0 \\
29.0 \\
29.0\end{array}$ & $\begin{array}{l}-15.0 \\
-15.0 \\
30.0\end{array}$ \\
\hline Common Areas & $\begin{array}{l}\text { Totally safe } \\
\text { To some extent safe } \\
\text { Not sure about safety } \\
\text { Total }\end{array}$ & $\begin{array}{l}14 \\
26 \\
47 \\
87\end{array}$ & $\begin{array}{l}29.0 \\
29.0 \\
29.0\end{array}$ & $\begin{array}{l}-15.0 \\
-3.0 \\
18.0\end{array}$ \\
\hline
\end{tabular}

Table 4. Hypothesis test summary using independent samples Kolmogorov-Smirnov test.

\begin{tabular}{llll} 
& Null hypothesis & Significance & Decision \\
1 & The distribution of concern about working in offices is the same across categories of gender. & 0.147 & Retain the null hypothesis. \\
2 & The distribution of concern about meeting rooms is the same across categories of gender. & 0.241 & Retain the null hypothesis. \\
\hline 3 & The distribution of concern about food and beverage areas is the same across categories of gender. & 0.163 & Retain the null hypothesis. \\
4 & The distribution of concern about restrooms is the same across categories of gender. & 0.001 & Reject the null hypothesis. \\
\hline 5 & The distribution of concern about using elevators is the same across categories of gender. & 0.633 & Retain the null hypothesis. \\
6 & The distribution of concern about common areas is the same across categories of gender. & 0.830 & Retain the null hypothesis. \\
\hline
\end{tabular}


meeting rooms, food and beverage areas, elevators, and common areas. As for concern about restrooms, the null hypothesis was rejected with $\mathrm{p}<0.001$ (at $1 \%$ level). It means there is a significant difference between male and female participants' opinions on the safety of restrooms.

\section{Discussion}

Overall, the participants in this study reported number of concerns in regard to the safety of the working from offices. During COVID-19 pandemic, the culture of offices has a significant shift, and many companies and offices switched to working from homes. However, this change impacts many aspects of work such as the working hours. A recent study in Netherlands found that total hours declined among self-employed and those with lower educational degrees, while workers with a tertiary degree worked a higher number of hours from home. ${ }^{14,15}$ Also, before the COVID-19 crisis, workers worked on average 29 hours at their workplace and four hours from home, while during the pandemic total hours worked had decreased by four hours, and now these hours are spent in equal shares at the workplace and at home. ${ }^{14,15}$

The result of this study showed gender differences concerning feeling in safe in the work environment; overall, males were slightly less concerned about safety than females. Concerns about the safety of using the restroom were significantly different between male and female participants. However, the highest concerns
$\mathbf{A}$

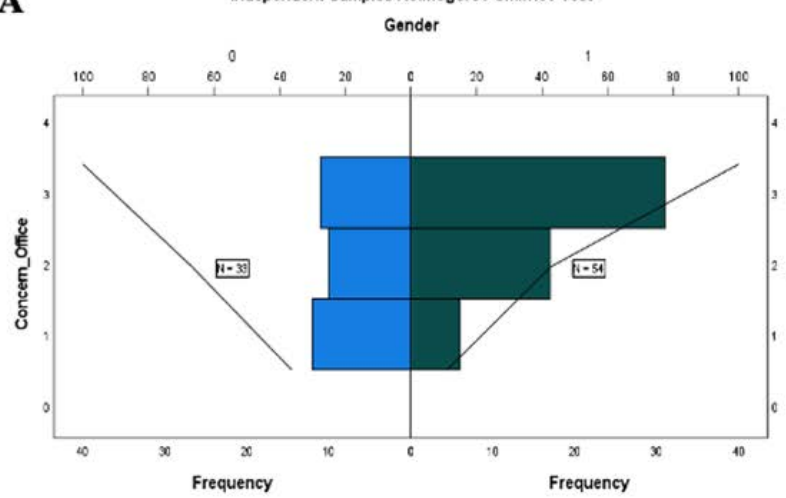

C

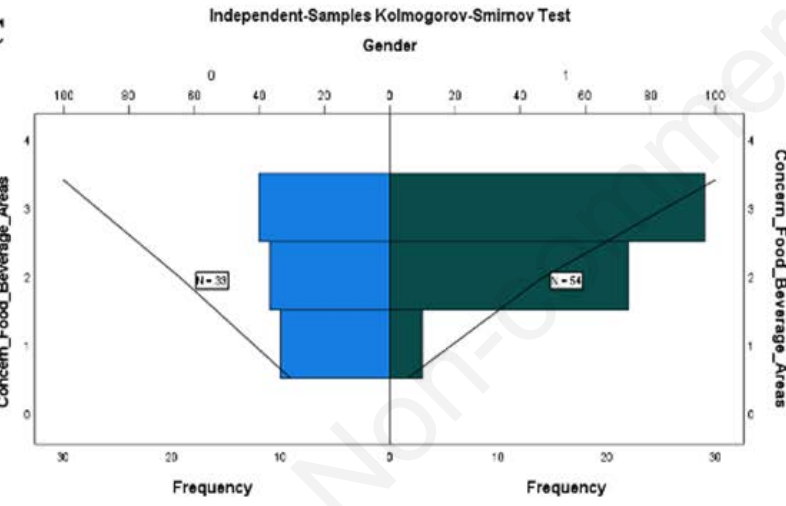

$\mathbf{E}$

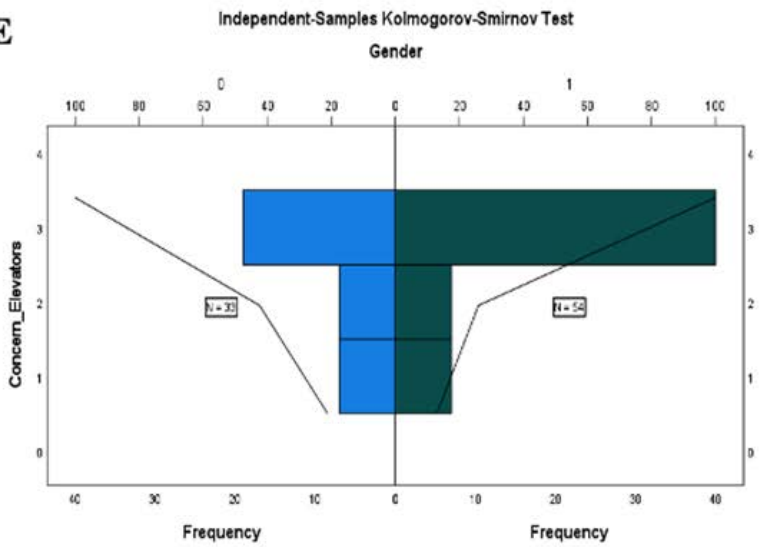

B
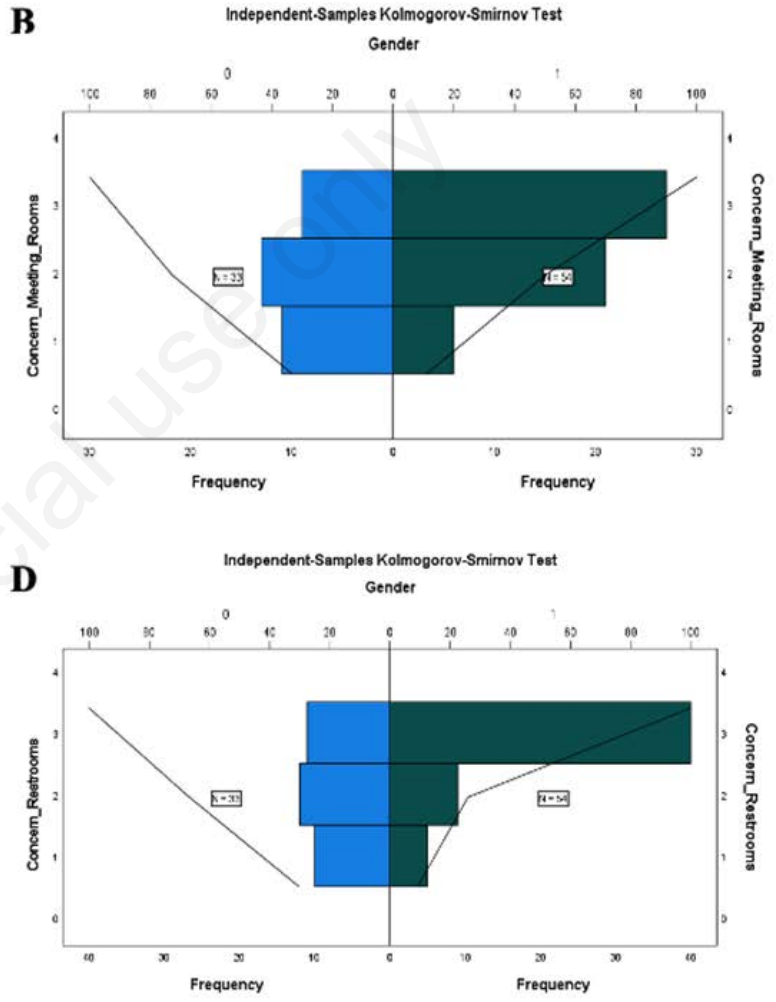

$\mathbf{F}$

Independent-Samples Kolmogorov-Smirnov Test

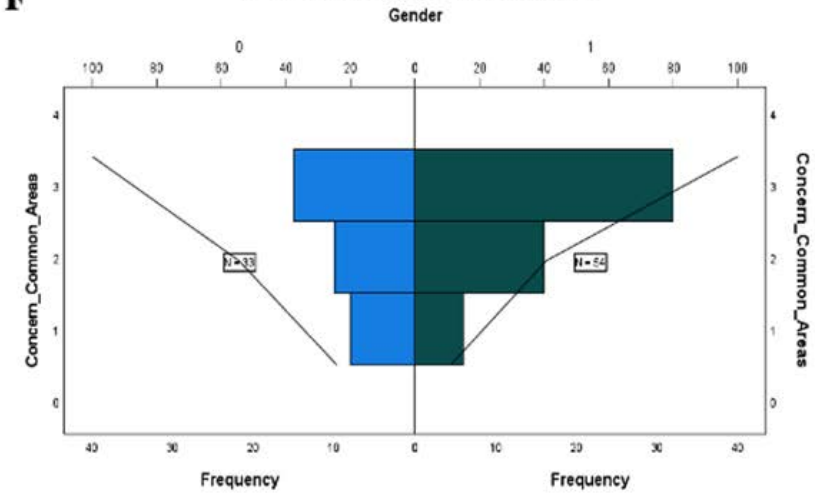

Figure 1. Independent samples Kolmogorov-Smirnov test. The figure shows the normality of all areas of concern including offices, meeting rooms, food and beverage areas, restrooms, elevators, and common areas. 
among both groups of participants were about using elevators, and then restrooms. As for the configuration of offices, participants didn't necessarily think that individual offices with four walls were totally safe. In contrast, some participants thought offices with low partition walls were quite safe. Overall, some workplaces have come back to work in their offices, while other firms think that about $40 \%$ of their workers who switched to remote work during the COVID-19 crisis would continue working remotely after it ends. ${ }^{13}$

One of the questions in the survey was an open question to participants asking them what aspects they would like to change or add in order to feel safe at work. The following section presents the main themes from this discussion.

\section{Number of employees}

It was suggested that the number of employees at the office during working hours could be reduced and some employees given tasks that could be done online. It was also suggested that shift working could be introduced or that those who share the same space could work different hours. In addition, it was suggested limiting the numbers using the elevators or increasing the number of elevators.

Certainly, the most effective way to stop the germs spreading in the work environment is to reduce the number of workers inside the building at one time. Firms might want to bring in certain teams at specific times to reduce crowding, instead of bringing in all workers during normal working hours. ${ }^{7}$ However, while working from home might reduce social contact, it might not be possible for all workers. ${ }^{6}$ One of the biggest challenges that workplaces face regarding assigning working hours or the selection of employees to work from home. Effective collaboration in not only making sure that employees log in for meetings and calls when they are supposed to, but spontaneous collaboration has a great role in innovations and creative solutions. Therefore, companies will need to provide a good collaborative framework, adopting meeting tools, chat apps and data sharing software, encouraging video calls and promoting casual interactions, which also can reduce the sense of isolation that people report when they work from home. ${ }^{15}$

\section{Hygiene and sanitizing protocol}

A number of suggestions were made about the quality of sanitization in the offices and the rest of the building, especially in the hallways and the elevators. One suggestion was hiring professionals to sanitize surfaces, and to sanitize every three hours, and after each use of the restrooms. Maintaining a hygiene and social distancing and calling people at workplace in urgent cases on alternate days should be addressed and HR needs to rethink on related issues such as motivating. ${ }^{15}$

\section{Office design}

Suggestions related to the design of spaces included: adding partitions between employees, providing good daylight and natural ventilation, enlarging office spaces and meeting rooms, or provide individuals offices with automatic doors.

Safety protocols require people to keep social distancing, which causes more demand for additional office space, so that workers are not as condensed as they used to be. ${ }^{7}$

\section{Working culture}

Suggestions related to the culture of working in offices includ- ed: the implementation of safe protocols for serving customers, not allowing staff to use each other's offices, less access to the offices of other departments, and switching to paperless work. According to Kaushik and Guleria, training and developing workers to learn new skills and technology to be competent, and to achieve current tasks more deeply, is required to fit into the changing scenario and economic landscape. ${ }^{15}$ Also, suggestions recommended respecting social distancing regulations, and implementing penalties for employees failing to comply with safety regulations, including workers who gather to chat or eat. It was also suggested holding all meetings virtually, reducing the number of working hours, removing all break times, and banning visitors from the building. However, one of the negative consequences that was mentioned in literature is employees feeling detached from his/ her company and lack the community feeling and attachment. Therefore, HR should play a significant role in connecting people. ${ }^{15}$

One of the participants' main concerns was the meeting room. However, conducting virtual meetings is one the simplest solutions that can be easily adopted in workplaces, and is implemented in many of them. This an example of how workplaces altered to increase remote working, as a result of COVID, and it showed how industries can adapt. These changes are likely to have implications for the nature of work in the coming years, ${ }^{13}$ in addition to the difficulties in managing and maintaining accountability of employees while working from home, which causes significant reduction in productivity and motivation. ${ }^{15}$ Based on the results of the study and prior literature, several suggestions are listed below:

- Create work hubs across the city to facilitate co-working spaces. ${ }^{15}$

- Use hygienic and anti-bacterial materials that can be easily sanitized. ${ }^{3,7}$

Improve ventilation systems, and UV lights for more deeply disinfecting for the office at night. ${ }^{7}$

Automation and voice technology to remove the need for physically pushing a button or touching a surface in an office. $^{7}$

- New design concept "Six Feet Office" which visually displays foot traffic routing in the office to keep people the recommended six feet apart. ${ }^{16}$

\section{Conclusions}

Prior studies showed that employers think that there has been less productivity loss from remote working in better educated and higher paid industries. In addition, more than one-third of firms that had employees switch to remote work believe that remote work will remain more common at their company even after the COVID-19 crisis ends. ${ }^{13}$ Companies will need to make certain that employees are well equipped to deal with remote working practices, and to provide support for individuals who do not have the required space or facilities at home. ${ }^{15}$ Therefore, designers should assess current office design and come up with creative solutions that accommodate workers' demands and ensure safety, and maybe altering the designs for residential spaces to accommodate these recent needs to work from homes. For instance, companies can create work hubs across the city to facilitate co-working spaces. ${ }^{15}$

One limitation of the current study is sample size. Larger studies could have provided further insightful information. Future studies could focus on larger sample sizes and comparative studies of work environments. 
Correspondence: Dr Rehab Aburas, Interior Design Engineering Department, College of Architecture and Design, Prince Sultan University, Rafha Street, PO Box 66833, Riyadh 11586, Saudi Arabia. Tel.+96.6114948744. E-mail: raburas@psu.edu.sa

Key words: COVID-19; work environment; Saudi Arabia.

Contributions: RA: designed the research, collected data, analysed data, and prepared original manuscript.

Conflict of interest: The author declares no potential conflict of interest.

Acknowledgements: The author thanks the participants for their involvement in the study. The author also acknowledges the support from Prince Sultan University for publication fees (article processing charges).

Ethics approval: This study was approved by PSU Institutional Review Board (PSU IRB). The approval no. was PSU IRB-2020-080053.

Funding statement: This research received no specific grant from any funding agency in the public, commercial or not-for-profit sectors.

Availability of data and material: Data are available upon request.

Received for publication: 27 Septmber 2020.

Accepted for publication: 9 January 2021.

o Copyright: the Author(s), 2021

Licensee PAGEPress, Italy

Journal of Public Health Research 2020; 9(s1):1968

doi:10.4081/jphr.2020.1968

This work is licensed under a Creative Commons Attribution NonCommercial 4.0 License (CC BY-NC 4.0).

\section{References}

1. Agius RM, Robertson JF, Kendrick D, et al. Covid-19 in the workplace. BMJ 2020;370:m3577. doi: 10.1136/bmj.m3577

2. Agius R. Covid-19 and health at work. Occup Med (Lond). 2020. doi: $10.1093 / \mathrm{occmed} / \mathrm{kqaa} 075$

3. Megahed NA, Ghoneim EM. Antivirus-built environment: Lessons learned from COVID-19 pandemic. Sustain Cities Soc 2020;61:102350. doi: 10.1016/j.scs.2020.102350

4. Zhang Y, Su X, Chen W, et al. [Epidemiological investigation on a cluster epidemic of COVID-19 in a collective workplace in Tianjin].[Article in Chinese]. Zhonghua liu xing bing xue za zhi 2020;41:649-53. doi: 10.3760/cma.j.cn112338-20200219-
00121.

5. Belzunegui-Eraso A, Erro-Garcés A. Teleworking in the context of the COVID-19 crisis. Sustainability 2020;12:3662. doi: $10.3390 /$ su12093662

6. Saadat S, Rawtani D, Hussain C. Environmental perspective of COVID-19. Sci Total Environ 2020;728:138870. doi: 10.1016/j.scitotenv.2020.138870

7. Molla R. This is the end of the office as we know it. Vox [Internet]. Accessed: 19 April 2020. Available from: https:/www.vox.com/recode/2020/4/14/21211789/coronavirus-office-space-work-from-home-design-architecture-realestate

8. Goniewicz K, Khorram-Manesh A, Hertelendy A, et al. Current response and management decisions of the European union to the COVID-19 outbreak: A review. Sustainability 2020;12:3838. doi: 10.3390/su12093838.

9. Papu S, Pal S. Braced for impact: Architectural praxis in a post-pandemic society. Advance 2020. Preprint doi: 10.31124/advance.12196959.v1

10. Hishan S, Ramakrishnan S, Qureshi M, et al. Pandemic thoughts, civil infrastructure and sustainable development: Five insights from COVID-19 across travel lenses. J Talent Dev Excell 2020;12(2s):1690-6.

11. Hern A. Covid-19 could cause permanent shift towards home working. The Guardian [Internet]. 2020. Available from: https:/www.theguardian.com/technology/2020/mar/13/covid19-could-cause-permanent-shift-towards-home-working

12. Marr B. How the COVID-19 pandemic is fast-tracking digital transformation in companies. Forbes [Internet]. 2020. Accessed: 1 April 2020. Available from: https://www.forbes. com/ sites/bernardmarr/2020/03/17/how-the-covid-19-pandemic-is-fast-tracking-digital-transformation-incompanies/?sh=1ee04973a8ee

13. Bartik AW, Cullen ZB, Glaeser EL, et al. What jobs are being done at home during the COVID-19 crisis? Evidence from firm-level surveys. National Bureau of Economic Research [Internet]. 2020. Available from: https://www.nber.org/ papers/w27422

14. Von Gaudecker HM, Holler R, Janys L, et al. Labour supply in the early stages of the CoViD-19 Pandemic: Empirical Evidence on hours, home office, and expectations. IZA Institute of Labor Economics. IZA Discussion Paper No. 13158 (April 2020). Available from: https://covid19.iza.org/publications/dp13158/

15. Kaushik M, Guleria N. The impact of pandemic COVID-19 in workplace. Eur J Business Manage 2020;12:9-18.

16. Cushman \& Wakefield [Internet]. 2020. 6 Feet Office. Accessed: 8 November 2020. Available from: https://www. cushmanwakefield.com/en/netherlands/six-feet-office 